\title{
Musika viva en Beethovenianas Momentum 11: conciertos de música electrónica y ambientes en Casa de la Cultura, año 1970
}

María Mercedes Herrera Buitrago'

Universidad Jorge Tadeo Lozano y Universidad Autónoma de Colombia

Artículo de reflexión derivado de investigación

Recibido: noviembre 9 de 2012 - Aprobado: noviembre 30 de 2012

\section{Resumen:}

Beethovenianas Momentum I / fue un evento de participación organizado por Musika viva en Bogotá, el cual tuvo como invitado a Musika Viva Ensemble de Nueva York. En este se dieron conciertos de música electrónica y ambientes escultóricos construidos de sonido, en medio de la utilización de innovaciones tecnológicas. Este artículo analizará Beethovenianas teniendo como fuentes documentales el programa de mano impreso tipo fanzine, las fotografías y los testimonios de algunos protagonistas. Con ello se apuntará a reconstruir este evento de participación en su relación con los movimientos artísticos internacionales, y con búsquedas escultóricas que se desarrollaron en Colombia.

Palabras clave: Musika viva, Musika viva ensemble, Beethovenianas, momentum, arte conceptual Colombia, historia del arte Colombia

\footnotetext{
Magistra en Historia de la Pontificia Universidad Javeriana, Grado Cum Laude y Orden al Mérito Javeriano (Bogotá, 2009); Maestra en Artes Plásticas de la Universidad Nacional de Colombia (Bogotá, 1999); e Historiadora de la Pontificia Universidad Javeriana (Bogotá, 2003). Autora del libro Emergencia del arte conceptual en Colombia. 1968-1982 editado por la Pontificia Universidad Javeriana en 20 I I. Ganadora de la Beca de Investigación en Artes Visuales del Ministerio de Cultura en 201 I con: Momentum: Gustavo Sorzano y el arte conceptual en Colombia. Ganadora del X premio de ensayo histórico, teórico o crítico sobre el campo del arte colombiano con la investigación Gustavo Sorzano: pionero del arte conceptual en Colombia. Actualmente es docente catedrática de la Universidad Jorge Tadeo Lozano e investigadora de la Universidad Autónoma de Colombia. mherrerabuitrago@gmail.com
} 


\title{
Musika viva em Beethovenianas Momentum 11: concertos de música eletrônica e ambientes na Casa da Cultura, ano 1970
}

\section{Resumo:}

Beethovenianas Momentum I / foi um evento de participação organizado por Musika viva em Bogotá, e que tive como convidado o Musika Viva Ensemble de Nova lorque. Nesse evento foram oferecidos concertos de música eletrônica e ambientes escultóricos construídos de som, isso dentro da utilização de inovações tecnológicas. $O$ presente artigo analisa Beethovenianas tendo como fontes documentais o programa de mão impresso tipo fanzine, as fotografias e as testemunhas de alguns protagonistas. Com isso tenta se reconstruir esse evento de participação na sua relação com os movimentos artísticos internacionais e com as buscas escultóricas desenvolvidas na Colômbia.

Palavras chave: Musika viva, Musika viva ensemble, Beethovenianas, momentum, arte conceitual Colômbia, história da arte Colômbia.

\section{Musika Viva in Beethovenianas Momentum 11 : electronic music concerts and environments in Casa de la Cultura, 1970}

\begin{abstract}
:
Beethovenianas Momentum I I was an event organized by Musika Viva in Bogotá featured by Musika Viva Ensemble from New York. In this event concerts of electronic music and sculpturing environments made up with sound in the midst of technological innovation. This article will analyze Beethovenianas resourcing to the printed fanzine hand program, the photographs and the testimonials of some of the participants. With this we will aim at reconstructing that participatory event in its relation to the international artistic movements and their sculpturing endeavors developed in Colombia.
\end{abstract}

Keywords: Musika viva; Musika viva ensemble; Beethovenianas; momentum; Colombian conceptual art; Colombian art history. 


\section{Introducción}

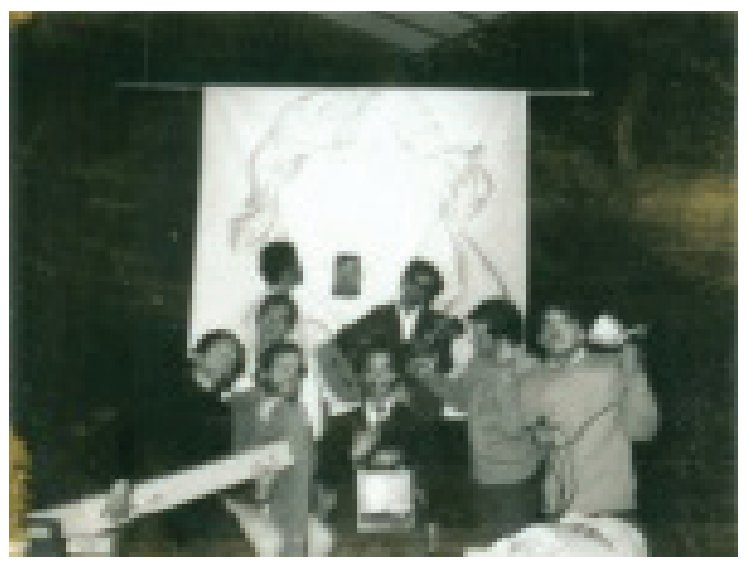

I. Musika viva y Musika viva ensemble, Beethovenianas, 1970. Fotografía sobre papel, Colección GUSTAVO SORZANO

Beethovenianas Momentum 11 fue el evento de participación realizado por Musika viva y Musika viva ensemble en la Casa de la Cultura dirigida por Santiago García -hoy Teatro La Candelaria- entre el 3 I de agosto y el I de septiembre de 1970. Evento de participación que ha sido desatendido e ignorado por la historiografía del arte en el país, y que a la luz de la investigación Música viva: eventos de participación en Colombia en la década del setenta² resulta fundamental para comprender la emergencia del arte conceptual en Colombia, dado que el desconocimiento sobre los orígenes o el inicio del arte conceptual en el país ha hecho que se privilegien pocos nombres de artistas (Bernardo Salcedo, Beatriz González, Álvaro Barrios, Antonio Caro, Miguel Ángel Rojas) y que se dejen de lado importantes actores cuyas propuestas son de gran riqueza conceptual, y tienen mucho que aportar a las búsquedas artísticas del presente ${ }^{3}$.

2 Música viva: eventos de participación en Colombia en la década del setenta es la investigación realizada por María Mercedes Herrera Buitrago entre enero de 2012 y enero de 2013, financiada por la Fundación Universidad Autónoma de Colombia, en la cual se aplican técnicas cualitativas como la entrevista en profundidad y la bola de nieve, además del análisis documental e iconográfico, y la digitalización de un volumen importante de documentación visual y sonora. Todo ello con el propósito de reconstruir los eventos de participación realizados por Musika viva, por considerarlos piezas importantes para comprender la emergencia del arte conceptual en Colombia.

3 A la fecha, entre las escasas publicaciones sobre el inicio del arte conceptual en Colombia se cuentan: Álvaro Barrios, Orígenes del arte conceptual en Colombia (Bogotá: Alcaldía Mayor de Bogotá, D.C., 1999); Carmen María Jaramillo. "Manifestaciones de la crisis del arte moderno en Colombia: 1968-1978". Tesis Maestría en Historia y Teoría de la Arquitectura y el Arte (Bogotá, Universidad Nacional de Colombia, 200 I); María Clara Cortés, "Acercamientos a la obra de Antonio Caro". Tesis Maestría en Historia y Teoría de la Arquitectura y el Arte (Bogotá, Universidad Nacional de Colombia, 200 I). Sobre un estado de la cuestión, ver, María Mercedes Herrera Buitrago, Emergencia del Arte Conceptual en Colombia (1968-1982) (Bogotá: Editorial Pontificia Universidad Javeriana, 201 I), págs. 18-25. 
Musika viva fue un grupo multidisciplinar y de creación plurisensorial dedicado a las exploraciones sonoras, que funcionaba en Bogotá y estaba ligado a la facultad de Arquitectura de la Pontificia Universidad Javeriana. Su poca divulgación y desconocimiento actual se puede explicar por varias razones: la falta de crítica de arte imperante a inicios de los años setenta en el país, cuyos intereses en galerías e instituciones artísticas imprimía en su oficio un tono subjetivo; el carácter efímero de las propuestas de Musika viva, los cuales se sentían comprometidos con la experimentación escultórica y sonora, no con el mundo del arte; los prejuicios con los que se ha hablado hasta el momento de arte conceptual en Colombia, rechazando lo que no sea pintura, escultura o gráfica, y considerando que la música no se relaciona con este tipo de arte. Es en esta dirección que el presente artículo se propone una mirada sobre Beethovenianas, cuya descripción y análisis aporte nuevos elementos en la comprensión de los inicios del arte conceptual en el país.

\section{Musika Viva}

En el año 1969, y al regresar de Estados Unidos, luego de cursar sus estudios en Arquitectura y Música en la Universidad de Cornell de Nueva York, Gustavo Sorzano ingresó al Instituto de Investigaciones Estéticas de la facultad de Arquitectura de la Pontificia Universidad Javeriana, donde quiso replicar su experiencia en Musika viva ensemble en un nuevo grupo llamado Musika viva. Así visto, Gustavo Sorzano convocó a docentes y estudiantes de las facultades de Arquitectura e Ingeniería electrónica, y con planteamientos similares a los expresados en los eventos desarrollados en la Universidad de Cornell, como la utilización de instrumentos atípicos como una aspiradora, un ventilador y una máquina Pin ball en Momentum $1^{4}$, y con la convicción de que la música es sonido organizado 5 , Sorzano y el recién gestado Musika viva desarrollaron su evento inaugural titulado Arquitectura del Sonido 6 .

Este primer evento de participación retomó el concepto momentum para numerar sus siguientes presentaciones, y así llegar al año siguiente, a la realización del momentum I I, como se numeró

4 Momentum / fue el evento inaugural de Musika viva ensemble. Se hizo en homenaje póstumo a Marcel Duchamp el 9 de diciembre de 1968 y se compuso de cinco actos. Sobre Momentum I, ver, María Mercedes Herrera Buitrago, "Gustavo Sorzano y el arte conceptual en Colombia: tres momentos vitales", Calle 14. Revista de investigación en el campo del arte 6, no. 8 (20 I2): I 44- I6I. Bogotá, Universidad Distrital Francisco José de Caldas. Los sonidos utilizados en Momentum I se encuentran en la Colección GUSTAVO SORZANO: Documento sonoro I, Material for Momentum One, cinta magnetofónica, 1968, digitalizados en formato WMA, duración: 18:03.

5 Música = Sonido organizado fue un concierto charla de música electrónica realizado el 4 de abril de 1968 en el auditorio de mecánica de la Universidad Industrial de Santander, donde Sorzano citó apartes de la conferencia "El futuro de la música-Credo" pronunciada por John Cage en 1937, en la academia de artes de Seattle. Ver, María Mercedes Herrera Buitrago, Gustavo Sorzano: pionero del arte conceptual en Colombia, X Premio de Ensayo histórico, teórico o crítico sobre el campo del arte colombiano, (en proceso de publicación por IDARTES); los documentos sonoros que recogen la conferencia y el concierto se encuentran en la Colección GUSTAVO SORZANO.: Documento sonoro 4, Música = Sonido Organizado, primera parte, cinta magnetofónica, 1968, digitalizado en formato WMA, duración: 33:13; y en Documento sonoro 5, Música = Sonido Organizado, segunda parte, cinta magnetofónica, 1968, digitalizado en formato WMA, duración: 28: 10.

6 Ver, María Mercedes Herrera Buitrago, "Arquitectura del Sonido: evento inaugural de Música Viva en Bogotá. Año 1969", Ensayos. Historia y teoría del arte, no. 22 (2012): 6-29. Bogotá, Universidad Nacional de Colombia. 
Beethovenianas. Momentum se refería a las teorías de la Relatividad Indeterminada y al Budismo Zen, en el sentido en que todo se encuentra en constante transformación y a que lo único que permanece es la impermanencia. También, para considerar que el espacio no es algo dado que deba ser ocupado, sino algo que se construye a través de la experiencia total de los sentidos.

De esta forma, Musika viva, que para el año setenta estaba compuesta por los arquitectos Gustavo Sorzano, su director, Rómulo Polo, su manager, y Samuel Bedoya, también músico, contaba con la participación de los estudiantes de arquitectura Fernando Noriega, Luis Fernando Barriga, Alfonso Herrán, Hernando González Arrázola -quien también era abogado-, Orlando Gómez Pico apodado "manitos de plata", Tristán Arbeláez Mendoza, Eduardo Fonseca y Aureliano Barbosa, la técnica en Arte publicitario María Teresa Montoya; el ingeniero Óscar Flórez. También se encontraban Rubén Ardila, Emilio Quevedo, Hernán Gutiérrez, Tristán Arboleda y Jon de Ocerín Alvarino, de quienes no se pudo encontrar información o establecer contacto durante la investigación. Todos ellos convocaron al grupo Musika viva ensemble de la ciudad de Nueva York, compuesto por su director David Shearer, Don Reinertsen, Jen Hubbel y Frederick Mangones, quienes viajaron a Bogotá a ejecutar Beethovenianas.

La prensa local lo reseñó de la siguiente manera:

MÚSICA ELECTRÓNICA - Un conjunto chileno, el Música Viva, hará hoy demostraciones de música electrónica en la Casa de la Cultura, a las seis y a las nueve de la noche. Como han tenido lugar tan extraños conceptos sobre música electrónica, seguramente estos recitales serán informativos y permitirá a la gente que conozca lo que está hablando?

Como se puede apreciar, el comentarista y crítico del arte y la cultura Manuel Drezner, cometió un error al afirmar que se trataba de un conjunto chileno. Sin embargo, no se puede desconocer que el mismo Drezner conocía bien a Musika viva, dado que esta agrupación había grabado en estudios Ingeson la pieza de música electrónica Zeguscua, y que un año antes, este crítico había reseñado las actividades de Gustavo Sorzano en su columna de prensa, destacando la originalidad y el talento del joven compositor ${ }^{8}$, y que errores de este estilo son comunes en las publicaciones periódicas.

Así pues, en la misma página de El Espectador aparecía la información correcta en las columnas que invitaban a eventos culturales, donde Musika viva pudo comunicar el tipo de aparatos electrónicos e invenciones tecnológicas que tendrían lugar esa noche en Beethovenianas. Entre estas cabe destacar el uso de instrumentos electrónicos como las grabadoras, los sintetizadores y pianos electrónicos, los moduladores de anillos y controles de sonido, el circuito cerrado de televisión, las cámaras Polaroid, además de instrumentos construidos por ellos mismos como los kotolines altos, medios y bajos, e instrumentos preparados como las guitarras.

7 M.D.T. [Manuel Drezner], "El arte y la cultura", El Espectador, I de septiembre de 1970, pág. 4 B.

8 DREZNER Manuel, "Arte y cultura", El Espectador, 3 de febrero de 1969. 
En contraste con este uso innovador de la tecnología del momento, e indagando de forma cuidadosa en la prensa del mismo día, aparece información sugestiva, que si bien no es categórica a la hora de hablar del uso de la tecnología del momento, puede colorear un poco el contexto de Beethovenianas. Se trata de una pregunta hecha por el señor Óscar Pardo al mismo Manuel Drezner en la sección "Preguntas y respuestas". El señor Pardo dice: "Deseo pintar la pantalla de mi televisor, pues estoy aburrido de ver todos los programas en blanco y negro ¿Qué clase de tintura debo utilizar?", a lo que Drezner responde:

Si de lo que se trata es de no ver los programas, la mejor pintura es la negra. $\bigcirc$ apagar el televisor. Pero si quiere cambiar el color a la programación, y verla por ejemplo verde, pruebe con papeles celofanes coloreados antes de echar una pintura que puede dañarle el televisor?

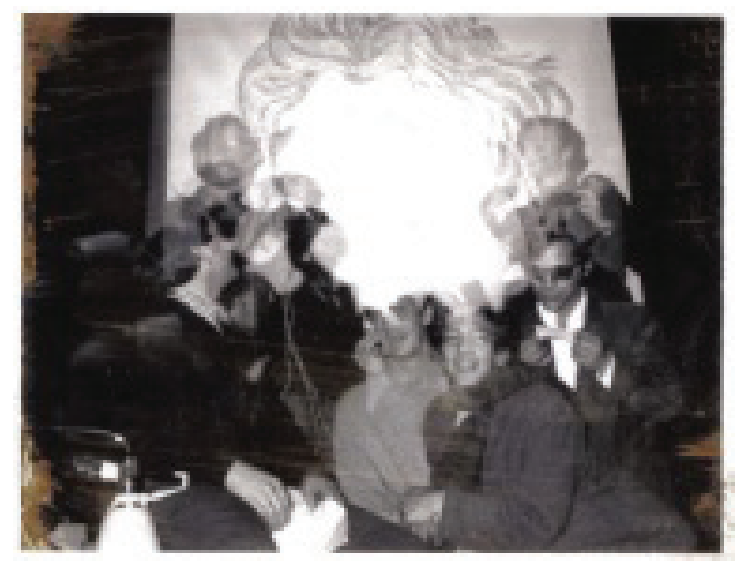

2. Musika viva y Musika viva ensemble, Beethovenianas, 1970.

Fotografía sobre papel, Colección GUSTAVO SORZANO

Esta breve información, además de inocua, logra ubicar el uso de la tecnología en el momento en que se ejecutó Beethovenianas. Aunque hoy en día los proyectores de opacos y de diapositivas resulten obsoletos, en 1970 resultaba una gran innovación que permitió a Musika viva proyectar el dibujo del rostro de Beethoven para interpretarlo como una partitura gráfica (llustr. 2). Asimismo, era completamente renovador y atípico el uso de aparatos electrónicos de complicada instalación para producir una experiencia sonora y ambiental (llustr. 3).

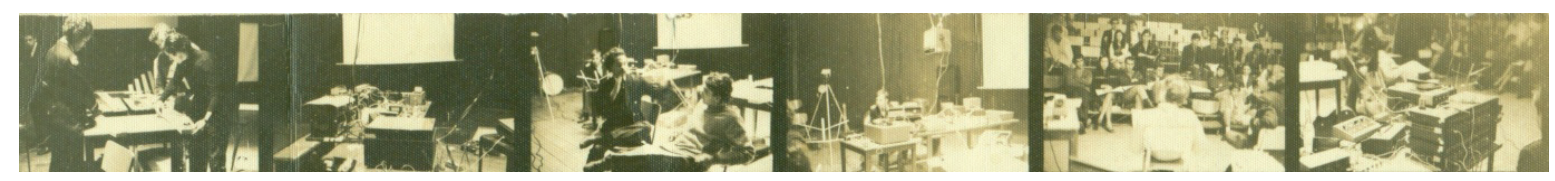

3. Musika viva y Musika viva ensemble, Beethovenianas, 1970 Hoja de contacto, Colección GUSTAVO SORZANO

$9 \quad$ DREZNER Manuel, "Preguntas y respuestas", El Espectador, I de septiembre de 1970. 
Beethovenianas, en la conjunción de la música electrónica y el teatro

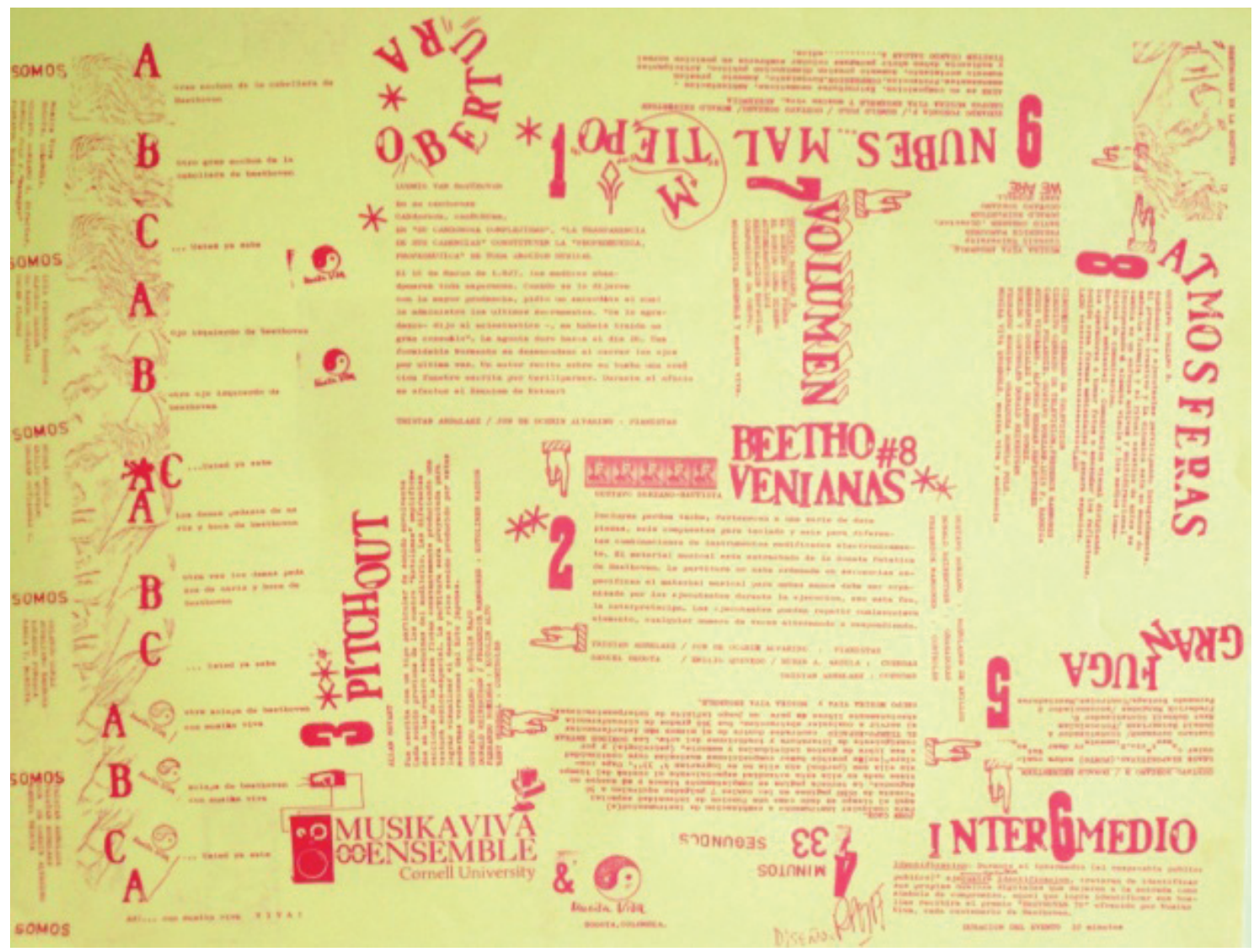

4. Musika viva y Musika viva ensemble, Beethovenianas, 1970. Programa de mano, impresión litográfica I x I tintas, 34 × $44 \mathrm{~cm}$. Colección GUSTAVO SORZANO

Beethovenianas fue un evento preparado con antelación. En primer lugar, se difundió la información básica en prensa, con lo cual se esperaba contar con un amplio público asistente; luego de lo cual se hicieron ensayos previos y se distribuyeron las actividades que requerían cada uno de los actos, se creó el orden del concierto electrónico y, además de ocuparse del traslado e instalación de los equipos electrónicos, se imprimió una especie de programa de mano, tipo fanzine, es decir, de bajo presupuesto y alta efectividad en la comunicación, para distribuirlo entre los asistentes en el momento de su llegada (llustr. 4 y 5).

Este programa de mano fue diseñado por Rómulo Polo, impreso a una sola tinta color magenta por ambas caras, sobre un papel semirígido beige, el cual, al ser leído y manipulado por los asistentes producía un sonido particular, que en sí mismo se constituía en un primer evento de participación. 
Por una de sus caras estaba impresa la información básica, con los nombres de los integrantes de ambas Musika viva, junto con el orden numerado de los actos que contendría Beethovenianas. Estos actos venían dispuestos de tal manera sobre el papel, que era necesario girar ortogonalmente, tanto en el sentido de las agujas del reloj como a la inversa, para poder encontrar la lógica de la escritura (llustr. 4). Al girar completamente el programa y apreciar la otra cara impresa, aparecían una serie de definiciones dispersas sobre lo que significaba Musika viva, y ciertas creencias sobre esta nueva práctica de la música electrónica y los sistemas de comunicación (llustr. 5).

Así, a la pregunta ¿qué es Música viva? los integrantes dieron sus respuestas, las cuales fueron consignadas bajo las iniciales de sus nombres que no siempre correspondieron a sus nombres y apellidos: con la inicial K Musika viva era "LA NAAA — RRRRIZZZ"; con la letra G, probablemente Gustavo Sorzano: "... DE TODO COMO EN BOTICA"; de seguro Polo con la letra R de Rómulo: "...LA OREJA"; tal vez María Teresa Montoya con las letras MT: "... COMO EN OTRAS PARTES"; es factible que Hernando González Arrázola con las letras HG dijera "SEVE, SE SIENTE ... SI" y más adelante: "TEXTURA PURA HEHEHEHE DURA RANURA Y POSTURA". Entre estas expresiones, otras tantas que mencionaban en sus respuestas caprichosas, lúdicas, de juego, que Musika viva era concurrencia, algo que gusta y disgusta, que es bello, collage, vida instante, environment, totalidad, participación, comunicación, exploración de espacios sicológicos, y entre todas estas expresiones había un espacio para llenar, decía USTED: es decir, qué era Musika viva para el espectador participante de Beethovenianas. Agregaron a esta definición de Musika viva un párrafo de un tono más formal donde aseguraron que la agrupación estaba compuesta de personas de distintas profesiones, como músicos, diseñadores, poetas y arquitectos, que no creían en los límites que separaban el arte y la vida. Y así, como estas respuestas aluden a la experiencia multisensorial, las palabras dispersas como "gusto", "tacto", "sonido", "imagen", aludían a los propósitos de Beethovenianas, excediendo el carácter de un concierto musical y tocando los terrenos escultóricos del happening y performance.

Volviendo el papel nuevamente a la cara impresa que contenía la numeración de los actos, se puede apreciar que estos conformaban una composición aleatoria y ordenada al mismo tiempo. Del acto I al 9 había que dar varias vueltas al papel apreciando un diseño estético similar al collage, con recortes de dibujos esquemáticos del busto de Beethoven, parlantes y equipos reproductores de sonido, y manos cuyo dedo índice señalaban el acto siguiente. Así, se puede afirmar que en el diseño había una fuerte incidencia de la poesía concreta y el collage cubista, al mismo tiempo, una idea de lo que se estaba produciendo en cuanto a tecnología. De frases como "conéctese usted aquí" dice hoy Sorzano mientras lee el programa:

Conéctese usted aquí, le hemos reservado este contacto" cuando no había... conéctese, hoy te conectarías tú a Internet, hubiéramos tenido esto de Internet de hoy en día, nosotros lo estábamos prefigurando en esa época, esto fue en Musika Viva con Cornell y Musika Viva en Bogotá [...] El programa ya es un evento porque 


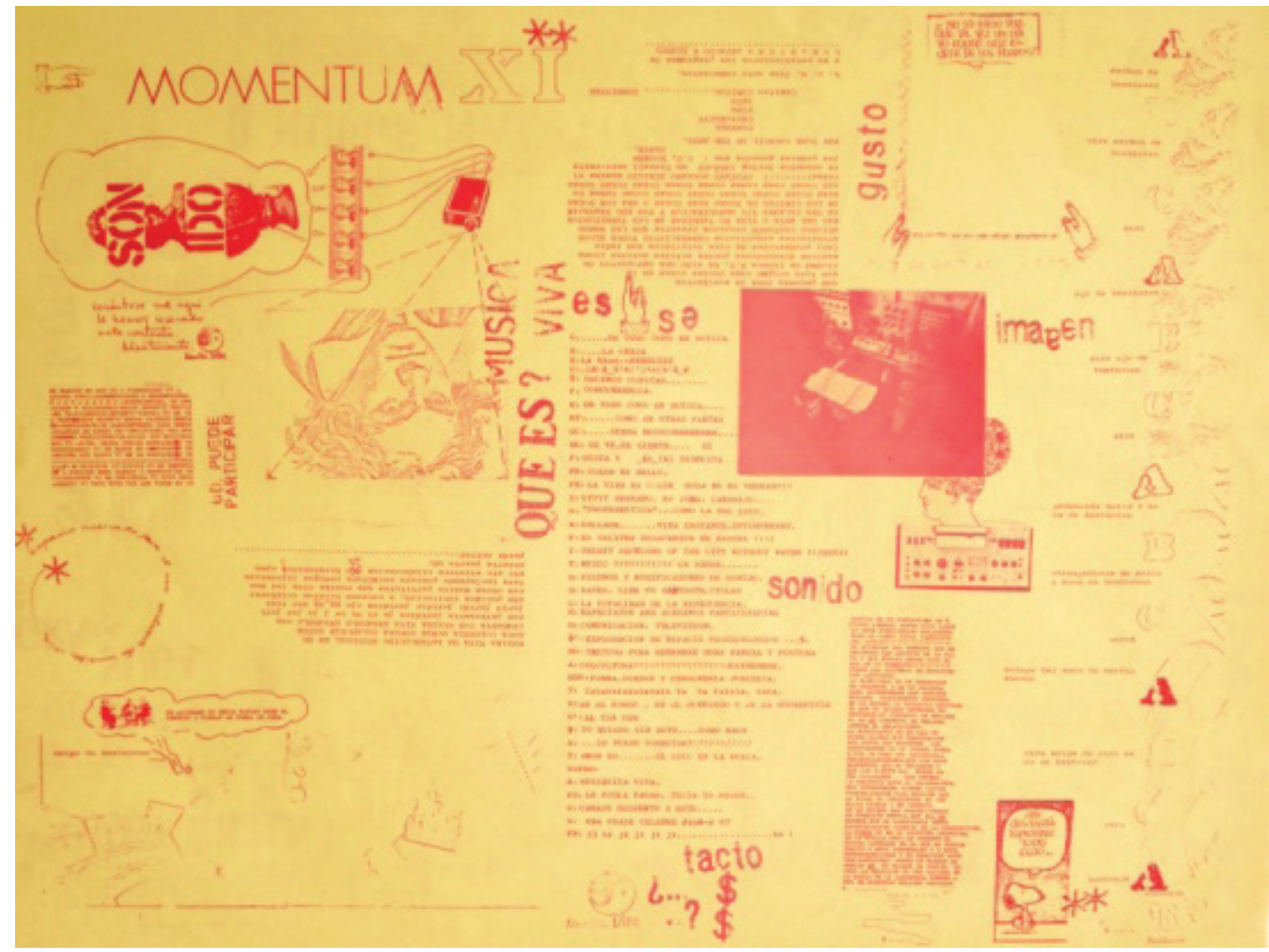

5. Musika viva y Musika viva ensemble, Beethovenianas, 1970. Programa de mano, impresión litográfica I x I tintas, 34 × $44 \mathrm{~cm}$. Colección GUSTAVO SORZANO

tú tenías que conectarte, en el teatro de Santiago García, ¿te puedes imaginar esto en eso tan revolucionario? ${ }^{10}$

Y es que no solamente era una innovación en la forma de hacer música, utilizando los aparatos electrónicos y sistemas de motivación que produjera la participación del público, también en el uso de los sistemas informáticos. Para el momento de la fundación de Musika Viva, Rómulo Polo recuerda que los ingenieros electrónicos que en principio se integraron como Óscar Flórez, Alejandro Barrero, Carlos Camacho y Antonio Dumit, estaban haciendo diseño de computadores. Según Polo:

I0 Conversación entre Gustavo Sorzano y María Mercedes Herrera, Ubaque, 9 de septiembre de 2010. 
Este grupo de estudiantes de ingeniería electrónica hacían parte de un equipo mayor que trabajaba en su tesis de grado en el diseño y construcción

del primer computador digital didáctico [CODIDAC] desarrollado en Colombia [1968-70, UJ] al cual ayudé $\{R P F\}$ en el diseño físico del equipo y sus aspectos de ergonomía y funcionalidad final del mueble que lo contenía [incluido lo que hoy denominan 'diseño de interfase']".

Al respecto, es preciso anotar que Hernando González Arrázola, estudiante de arquitectura de la Universidad de Los Andes, y de derecho en la Universidad Santo Tomás, quien era una promesa en la política y ejercía un cargo público, aprovechaba su tiempo libre para experimentar cómo traducía el lenguaje binario del computador imágenes como la Odalisca de Ingres. Esto produjo una serie de pinturas en acrílico sobre tela, en módulos rectangulares, según González Arrázola:

Eso lo hice en el año setenta [...] Eso lo hacía en el computador porque yo trabajé también en el Ministerio de Hacienda entonces allá tenía un computador gigante, entonces por la noche iba yo a hacer estas cosas en computador [... ] tenía la imagen entonces la pasaba a puntos y ceros, entonces lograba estas cosas [tenía los modelos impresos sobre papel] y los pasaba grandes a estas cosas [...] se podía jugar con ellas [...] las podías poner horizontales y son un paisaje, las puedes alternar, combinan perfectamente y encajan unas con otras ${ }^{12}$.

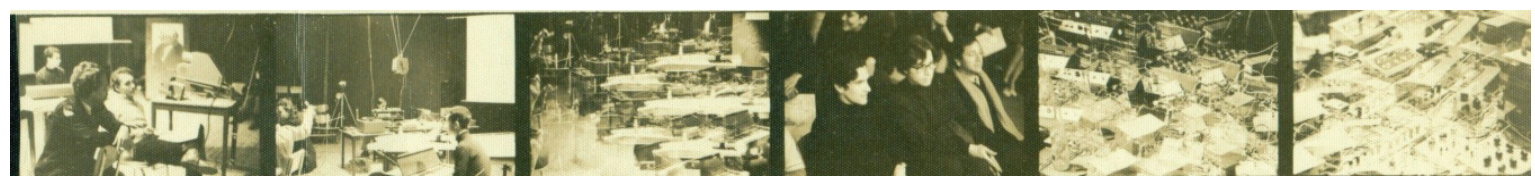

6. Musika viva y Musika viva ensemble, Beethovenianas, 1970. Hoja de contacto, Colección GUSTAVO SORZANO

Así visto, en el uso tecnológico de Beethovenianas se reunían inquietudes afines de los integrantes de Musika viva; adicionalmente un patrón composicional que Sorzano ya había realizado en eventos anteriores - en Momentum I el primer acto se tituló Beethovenianas III \& IV; y en Música= Sonido organizado la pieza Beethoveniana para piano preparado-, el cual consistía en sustraer partes significativas de las partituras originales de Beethoven para obligar a los intérpretes a la improvisación. Para Sorzano, Beethoven fue el primer músico que realizó experimentaciones sonoras, pese a su problema auditivo, lo cual hizo de este el gran improvisador de la música occidental'3.

II Rómulo Polo, correo electrónico recibido por María Mercedes Herrera, noviembre de 20I2. Los signos como paréntesis, corchetes y abreviaciones son de Polo.

12 Conversación entre Hernando González Arrázola y María Mercedes Herrera, Bogotá, 6 de septiembre de 2012.

13 Conversación entre Gustavo Sorzano y María Mercedes Herrera, Ubaque, 9 de julio de 201 I. 
Pero, a diferencia de las Beethovenianas anteriores, este evento de participación estaba dedicado exclusivamente a Beethoven.

Beethovenianas se compuso de nueve actos, unos fueron conciertos de música electrónica, otros fueron ambientes de luz, sonido y movimiento, y algunos consistieron en la mezcla de ambos, y aunque tanto Musika viva como los asistentes al evento contaron con el programa de mano con indicaciones sugerentes, carecían de indicaciones de tiempo establecido o de actividades completamente definidas. Por ello debieron entregarse de lleno a un juego de duración y tiempo y darse al primer acto titulado Obertura, interpretado al piano por Tristán Arbeláez y Jon de Ocerín Alvarino. El impreso decía:

Ludwing Van Beethoven

En su candorosa

CANdoroda, candorosa, EN "SU CANDOROSA COMPEJIDAD", "LA TRASPARENCIA

\section{DE SUS CADENCIAS" CONSTITUYEN LA "PROPEDEUTICA, PROPEEUTICA" DE TODA EMOCIÓN MUSICAL}

El 16 de Marzo de 1.827, los médicos abandonaron toda esperanza. Cuando se lo dijeron con la mayor prudencia, pidió un sacerdote el cual le administro los últimos sacramentos. "Os lo agradezco- dijo al eclesiástico -, me habeis traido un gran consuelo". La agonia duro hasta el dia 26. Una formidable tormenta se desencadeno al cerrar los ojos por ultima vez. Un autor recito sobre su tumba una oración fúnebre escrita por Gerillparzer. Durante el oficio se efectuo el Requiem de Mozart

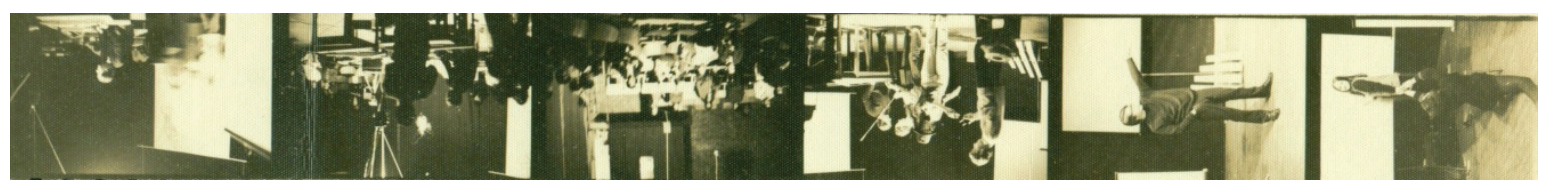

7. Musika viva y Musika viva ensemble, Beethovenianas, 1970. Hoja de contacto, Colección GUSTAVO SORZANO 
Luego de esta primera interpretación musical vino el segundo acto titulado Beethovenianas \#8, donde Musika viva utilizó extractos de la Sonata Patética de Beethoven. Este acto fue interpretado al piano por los mismos intérpretes de Obertura Tristán Arbeláez y Jon de Ocerín Alvarino, pero en la sonoridad agregaron instrumentos de cuerdas interpretados por Samuel Bedoya, Emilio Quevedo, Rubén A. Ardila, y Tristán Arbeláez, este último debió ejecutar ambos instrumentos; en el modulador de anillos se encontraba Gustavo Sorzano; en el manejo de las grabadoras que reproducían fragmentos de cintas magnetofónicas Donald Reinertsen; y a cargo de los controles de todos los aparatos electrónicos estaba Frederick Mangones.

Decía el impreso:

Incluyen perdón tache, Pertenecen a una serie de doce piezas, seis compuestas para teclado y seis para diferentes combinaciones de instrumentos modificados electronicamente. El material musical esta extractado de la Sonata Patetica de Beethoven. La partitura no está ordenada en secuencias especificas el material musical para ambas manos debe ser organizado por los ejecutantes durante la ejecución, eso esta feo, la interpretación. Los ejecutantes pueden repetir cualesquiera elemento, cualquier numero de veces alternando o respondiendo.

Como tercer acto vino Pitch Out de Allan Bryant, el cual consistió en la proyección de diapositivas de texturas sobre la pared (llustr. 8), acompañada de la ejecución de cuatro kotolines ubicados por distintas partes del auditorio con el propósito de descentrar el sonido y crear un ambiente. Las diapositivas eran interpretadas por los ejecutantes, quienes tocaban los kotolines con baquetas, especie de koto japonés o caja de resonancia rectangular que puede componerse de 13 a 80 cuerdas. Los kotolines dispuestos horizontalmente hacían que los ejecutantes tuvieran que emplear las dos manos, con la izquierda presionaban las cuerdas hacia la base, con la derecha las pulsaban (llustr. 9).

Decía el impreso:

Fue escrita con un tipo particular de sonido envolvente Cada sonido proviene de los cuatro "kotolines" amplificados en las cuatro esquinas del auditorio. Las diferentes secciones de la pieza flotan constantemente produciendo una textura sónica-espacial. La partitura será proyectada para lograr visualizar el denso y rico sonido producido por estas modernas visiones del Koto japonés. 

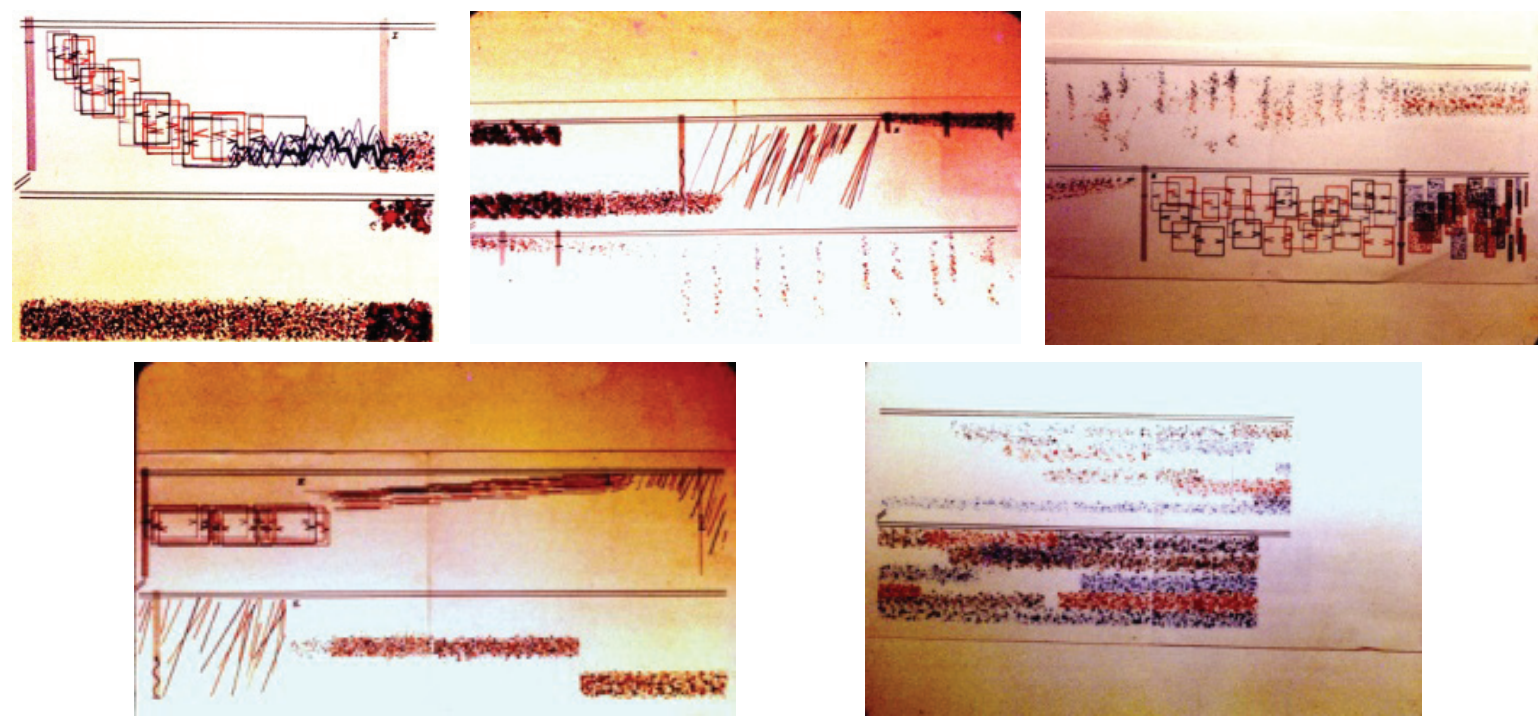

8. Musika viva y Musika viva ensemble, Beethovenianas, "Pitch Out", 1970.5 diapositivas, Colección GUSTAVO SORZANO

Para Pitch out se utilizaron kotolines altos, medios y bajos. Estos eran construidos por los integrantes de Musika viva, especialmente por Orlando Gómez Pico "manitos de plata", a quien todos reconocían su habilidad para moldear y manejar diferentes materiales. Los kotolines eran creados utilizando cuerdas de guitarra o de piano (llustr. 9). Gómez Pico lo recuerda de la siguiente manera:

el 'kotolin' simplemente eran unas tablas largas, pero con una caja de resonancia y jalábamos unas cuerdas de piano y las tensábamos con los tensores con los que se sustentan las cuerdas de acero para los puentes y entonces lo poníamos a vibrar en unos sabores de..., en otras..., muy lindo, también colgábamos picas, palas [...] el 'kotolin' alto era con cuerdas delgadas, el bajo era con cuerdas gruesas. Eran invenciones de Gustavo y todos le seguíamos la cuerda'4.

Los kotolines eran interpretados según la duración del evento y la interpretación que cada cual diera a la textura proyectada en la pared. Esta interpretación estuvo a cargo de Fernando Noriega en el kotolin alto, Donald Reinertsen y Frederick Mangones en los kotolines medios y Gustavo Sorzano en el kotolin bajo. Los controles del sonido estuvieron a cargo de Kent Hubbel. Con ello se buscó crear un ambiente de sonido, luz y textura, una atmósfera sutil que, acompañada de partituras gráficas completamente abstractas, se convirtieran en un pretexto obligado para la improvisación, y que sumergieran a los espectadores en un concierto no tradicional, dado que quienes producían el sonido no se encontraban en un foco central del escenario, sino estaban dispersos por el auditorio.

I4 Conversación entre Orlando Gómez Pico y María Mercedes Herrera. Bogotá, 22 de julio de 201 I. 


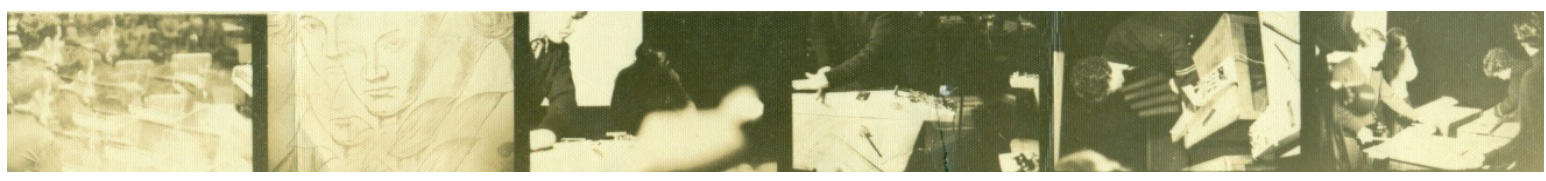

9. Musika viva y Musika viva ensemble, Beethovenianas, 1970. Hoja de contacto, Colección GUSTAVO SORZANO

Como acto siguiente 4'33" interpretado por ambas Musika viva junto a los asistentes del evento. Decía el impreso:

JOHN CAGE. Para cualquier instrumento o combinación de intrumentod(s) aquí el tiempo es dado como una función de intensidad espacial *consta de $\mathrm{OCHO}$ paginas en las cuales 7 pulgadas equivalen a 56 segundas. La tercera pagina es completamente blanca y [tachones] aunque no tiene nada en ella esta extendiad espacialmente al conteo del tiempo sin ella nom (perdón) sin ella no se lograrían 4' 33". Cage concluye "(no) Es posible hacer composiciones musicales cuya continuidad $x$ sea libre de gustos individuales y memoria, (psicología) y por consiguiente de literatura y tradiciones del arte. LOS SONIDOS ENTRAN EL TIEMPO-ESPACIO centrados dentro de si mismos sin interferencias al servir a cualquier abstracción. Sus 360 grados de circunferencia absolutamente libres [tachones] para un juego infinito de interpenetraciones.

En este acto, Musika viva ejecutó una de las composiciones más polémicas del norteamericano John Cage, dado que en 4'33" Cage aplicó los conceptos de indeterminación y no intencionalidad al punto de construir una partitura conformada por tres partes, señaladas con números romanos en cuya interpretación el pianista David Tudor no produjo ningún sonido, solo el abrir y cerrar la tapa del piano en los tiempos determinados de 33 segundos, dos minutos cuarenta segundos, un minuto veinte segundos. Esta pieza fue estrenada el 29 de agosto de 1952 en Woodstock, y consistió en un homenaje al silencio. Para ello, Cage se basó en su experiencia al introducirse en una cámara anecoica en la Universidad de Harvard, donde contrario a lo que esperaba, escuchó dos sonidos: uno agudo proveniente de su sistema nervioso, y uno grave producido por su sistema circulatorio. De allí concluyó que el silencio es la reunión de los sonidos que no están organizados en una composición ni notados en las partituras musicales, no lo contrario al sonido.

Al igual que en 4'33" de Cage, en este cuarto acto de Beethovenianas lo que se escuchó durante este tiempo determinado fueron los sonidos del ambiente: los movimientos con los programas de mano, las risas y murmullos del público, el crujir de las sillas y del piso. Rómulo Polo la recuerda de la siguiente manera: "eso era totalmente, John Cage..., eran minutos de silencio"15.

15 Conversación entre Rómulo Polo y María Mercedes Herrera. Bogotá, 19 de enero de 2011. 
Como quinto acto estuvo Gran Fuga, compuesta por Gustavo Sorzano y Donald Reinertsen. Decía el impreso:

\title{
LEASE DIAPOSITIVAS. (PUNTO) sobra cual-
}

quier comentario. Elementary dear Watson...

Las diapositivas no se conservan, pero se sabe que consistió en una interpretación de música electrónica donde se utilizaron dos sintetizadores, fotocélulas, secuenciadores y controles y mezcladores de sonido. Este acto estuvo a cargo de Gustavo Sorzano en el sintetizador A y Kent Hubbell el sintetizador B; Donald Reinertsen en las fotocélulas; Frederick Mangones en el secuenciador; y en los controles y mezcladores Fernando Noriega.

Luego de esta presentación vino Intermedio donde el público debía identificar sus huellas digitales. Según Sorzano:

Ah! Y estos al entrar, al entrar las personas tenían que dejar la huella digital, luego en el intermedio mire lo que hacían: "durante el intermedio el respetable público ejecutará identificación que consiste en tratar de identificar sus propias huellas digitales que dejaron a la entrada como símbolo de compromiso, aquel que logre identificar su huella recibirá el premio Beethoven 70"'6.

Este intermedio tuvo una duración de 10 minutos, donde el público se levantó de sus sillas, conversó, se rió, y no se sabe si alguno pudo identificar sus propias señales ni en qué consistía el prometido premio.

Más adelante, el séptimo acto llamado Volumen, decía el texto:

\author{
EL SONIDO COMO FORMA \\ EL SONIDO COMO DISEÑO \\ AUTODIRECCION. LUZ \\ REINSTALACION ESPACIAL \\ COMPOSICION DE GRUPO
}

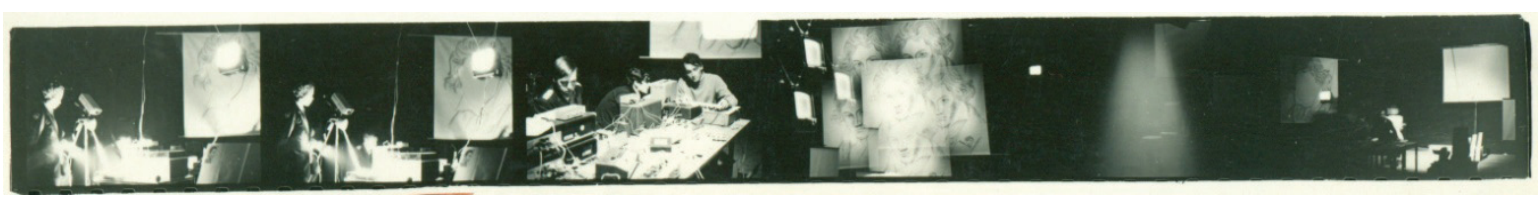

10. Musika viva y Musika viva ensemble, Beethovenianas, 1970. Hoja de contacto, Colección GUSTAVO SORZANO

16 Conversación entre Gustavo Sorzano y María Mercedes Herrera. Ubaque, 9 de septiembre de 2010. 
Para la creación de Volumen se privilegió el dibujo del rostro de Beethoven, el cual, por efectos del proyector de diapositivas creaba un volumen circular y pleno de dinamismo en un juego de luces y sombras (llustr. 10). Con ello, Musika viva creó una atmósfera de sonidos, luz y tiempo, sin un propósito establecido, sin un carácter específico que obedeciera los deseos de un compositor en particular ni de ningún participante en general.

Como octavo acto estuvo Atmósferas. Para este, el texto indicaba lo siguiente:

Aundoencia y ejecutantes participando integradamente.

El proceso creativo y la dinámica esta en manos de ambos. La formula y el ritual estático de antes se cambia en un enfoque activo y mutidireccional incorporando el elemento visual y los medios inmediatos de comunicación.

En-foque ambiental. Comunicación visual dirigiendo los operadores a tomar fotos o encender reflectores. Sonido crea formas ambientales y genera espacios. LADO ********** $[16$ * $]$ LADO

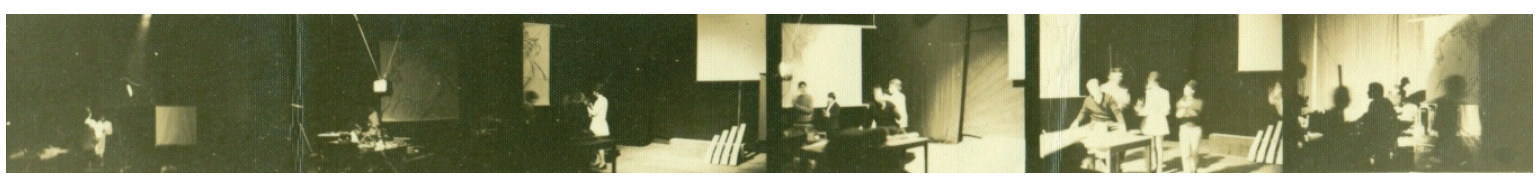

II. Musika viva y Musika viva ensemble, Beethovenianas, 1970, Hoja de contacto, Colección GUSTAVO SORZANO

En este acto se pusieron en juego las proyecciones de luz utilizando las antorchas y los medios audiovisuales como la proyección de diapositivas. Además, se tomaron fotografías con cámara Polaroid que eran proyectadas en los proyectores de opacos, y con las cámaras de televisión se filmaba a las personas del público que inmediatamente veían su imagen dentro del escenario. Con esto se establecía todo un juego de participación y de dinamismo de los espectadores quienes, a esta altura de Beethovenianas, ya estaban tan inmersos dentro de la actividad creativa que habían roto con el papel convencional de quien contempla una obra artística (llustr. I I).

El último acto se tituló Nubes... mal tiempo, en el cual los asistentes, a quienes se les había pedido que fueran en "traje de lluvia", debían vestir sus abrigos, poner los sombreros sobre sus cabezas y abrir sus paraguas, acto seguido, salir del auditorio. Decía el impreso: 


\begin{abstract}
AIRE es su composición. Estructuras neumáticas. Ambientacion . amenazantes. Proteccion. COMPRESION.Movimiento. Aumento presión aumento movimiento. Aumento presión disminución publico. Articipantes y audiencia deben abrir paraguas colocar sombreros en posición normal TIRITEN CUANDO SALGAN A............adios.
\end{abstract}

Así visto, Beethovenianas estaba del lado de las rupturas de los géneros artísticos y de lo que había ocurrido en el mundo del arte a nivel internacional, tanto en la aplicación de técnicas y procedimientos electrónicos y en la introducción del ruido de las máquinas en el campo musical, como en la integración escultórica del espacio arquitectónico para habitar. De este modo, lo que en principio sería un concierto musical, se transformaba de repente en una obra que se producía en tiempo y espacio reales, abierta a la participación del público, que no se cosificaba ni podía trasladarse a ningún lugar en específico, experiencia convertida en momentum, y como tal, irrepetible. Cuando se interroga a Gustavo Sorzano por el sentido de este evento de participación, el responde que la idea es que siempre fuera diferente, y si alguien quisiera tomar los mismos materiales e indicaciones y rehacer Beethovenianas, produciría otras cosas ${ }^{17}$, es decir, el resultado de esta actividad pasa a un segundo plano y gana total relevancia el proceso. Como ya se ha anotado, aunque hubo ensayos previos y programación, Beethovenianas funcionó como un juego sometido a reglas, pero estas últimas eran tan elásticas, que valdría la pena llamarlas sugerencias o indicaciones.

\title{
Trascendencia de Beethovenianas
}

En Beethovenianas, Musika Viva se ubicó del lado del trabajo desarrollado por John Cage y su influencia ejercida en jóvenes músicos como Morton Feldman, Earle Brown y Christian Wolff en la medida en que tomaron ideas de las artes visuales y el legado de las vanguardias artísticas, principalmente del Dadaísmo y el Futurismo. A su vez, Musika viva tuvo una relación marcada con los desarrollos del alemán Karlheinz Stockhausen y su "música intuitiva", lo cual puede notarse en obras como Aus den sieben Tagen (De los siete días) de 1968, donde el compositor pidió al intérprete que improvisara sobre textos escritos, y en el conjunto Plus/Minus de 1963, Prozession de 1967 y Kurzwellen de 1968, donde Stockhausen alentó al intérprete a improvisar sobre material compuesto de sus propias composiciones anteriores, fragmentos de obras de Beethoven y transmisiones de onda corta ${ }^{18}$. Musika viva también se ubicó del lado del grupo inglés AMM fundado en 1965, y del conjunto norteamericano radicado en Roma Música electrónica viva MEV de 1966, no solo en la concordancia con su nombre, sino en la medida en que introducían en sus conciertos instrumentos

17 Conversación entre Gustavo Sorzano y María Mercedes Herrera. Ubaque, 9 de septiembre de 2010.

I8 Sobre la influencia de John Cage en músicos norteamericanos y europeos, ver, Robert P. Morgan, La música del sig/o XX (Madrid: Ediciones Akal, S.A., 1994), págs. 379-398. 
no tradicionales y productores de sonido electrónico y no convencional, e invitaban al público a hacer parte de la interpretación.

De esta manera, Musika viva estaba del lado de la indeterminación en la medida en que utilizaron el azar, tanto en la composición como en la interpretación musical, además, porque entendían la música como organización de sonido, el cual puede componerse tanto de los sonidos de la naturaleza como de las máquinas. Desde esta consideración, Musika viva adoptó los nuevos métodos de producción musical en las modalidades de escritura, composición e interpretación, al utilizar partituras gráficas que rompían con los esquemas convencionales y los límites de la escucha, y al introducir preocupaciones sobre el espacio desde la arquitectura, el diseño y el arte plástico. En consecuencia, Musika viva apostó por la multidisciplinariedad y la no especialización, otorgando un inusitado protagonismo a los medios magnéticos, mecánicos y lumínicos en la producción sonora.

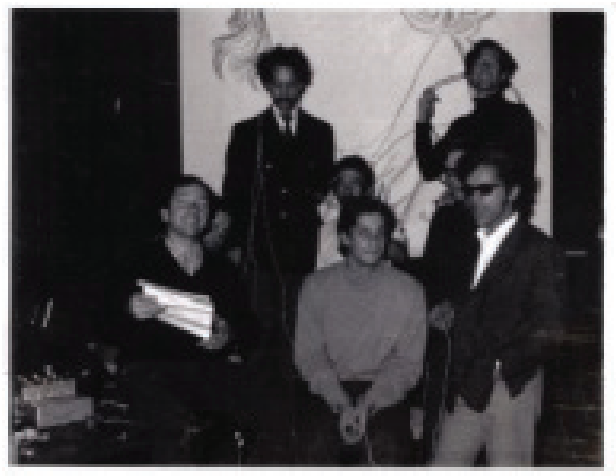

9. Musika viva y Musika viva ensemble, Beethovenianas, 1970. Fotografía sobre papel, Colección GUSTAVO SORZANO

Es de anotar que a nivel nacional, en el campo de la música electrónica se distinguían Blas Emilio Atehortúa, David Feferbaum, Fabio González Zuleta, Francisco Zumaque y Jacqueline Nova Sondang ${ }^{19}$. A finales de los sesenta, esta última había realizado trabajos en colaboración con las escultoras Feliza Bursztyn en la obra Las camas, y Julia Acuña en Sonido, luz y movimiento. A su vez, había realizado la música para las obras de teatro Macbeth, dirigida por Enrique Buenaventura y Julio César, dirigida por Jorge Alí Triana. Pese a estas coincidencias, Beethovenianas estuvo más cercano al principio de creación colectiva que llevaba a cabo el teatro experimental realizado por Santiago García, para quien, este principio era un sistema de trabajo dominante en aquella época: "el que no hubiera un autor sino que el grupo, muy consolidado ya que teníamos, fuera el autor de las obras, yo dirigía, pero no

19 Sobre la música electrónica y concreta en Colombia, ver, Mauricio Bejarano, "I965. Música electroacústica colombiana.2006", en Gustavo Zalamea ed., Arte y localidad modelos para desarmar. (Bogotá: Universidad Nacional de Colombia, 2006), págs. 27-35. 
me inventaba, la primera obra que hicimos entonces se llamaba Nosotros los comunes, era una obra sobre la Revuelta de los Comuneros"20.

Conjuntamente, Beethovenianas coincidió con esta exploración teatral en el trabajo escultórico y escenográfico: en los nueve actos, los signos eran literales, no miméticos ni metafóricos. Así, las proyecciones de luz en diapositivas, sus juegos y movimientos eran solamente eso, no significaban nada distinto, y a pesar de que ideológicamente estaban ubicados en orillas distintas en tanto que Santiago García tenía un marcado compromiso político, a diferencia de Musika viva, grupo que aunque buscara la participación del público, la democratización de la experiencia artística y quisiera hacer una revolución musical, no estaba interesado en involucrarse con las facciones políticas de izquierda.

No obstante, Beethovenianas se dio en este espacio artístico, al parecer por una circunstancia particular: Gustavo Sorzano y Santiago García trabajaban juntos en Leo Burnett, la empresa de publicidad más importante en el momento, y aunque no coincidieran en la apreciación de la necesidad de un arte "auténtico" o "nacional", estaban involucrados en la búsqueda de un arte que fuera un trabajo conjunto, un hacer que estuviera ligado con la vida en la celebración de lo ordinario, de lo cotidiano, en la vivencia del tiempo unas veces acelerado debido a lo sorpresivo e inesperado de los eventos, otras veces lento en función de lo conocido.

Además, entre Beethovenianas y el teatro experimental mediaban las inclusiones y apropiaciones de nuevos procedimientos creativos y conceptos filosóficos que revaluaron el rol del artista, el papel de los espectadores, la estabilidad del escenario, la precariedad de la escenografía. Todo ello enfocado en hacer de la obra de arte, fuera musical, plástica o teatral, una experiencia multisensorial y emotiva que evidenciara que el arte es un trabajo ligado a la vida.

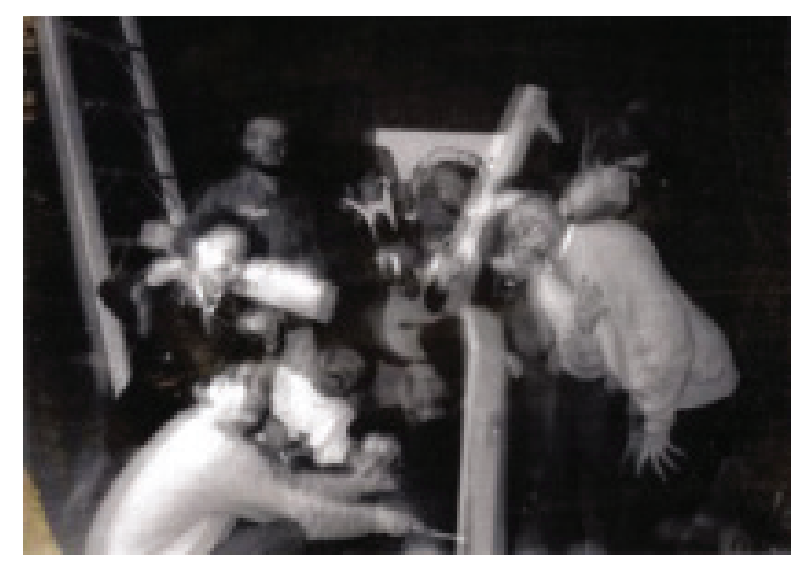

10. Musika viva y Musika viva ensemble, Beethovenianas, 1970. Fotografía sobre papel, Colección GUSTAVO SORZANO

20 Conversación entre Santiago García y María Mercedes Herrera. Bogotá, I8 de enero de 20 I I. 


\section{Referencias}

\section{Fuentes primarias}

\section{Entrevistas}

Conversación entre Gustavo Sorzano y María Mercedes Herrera, Ubaque, 9 de septiembre de 2010.

Conversación entre Santiago García y María Mercedes Herrera. Bogotá, 18 de enero de 201 I.

Conversación entre Rómulo Polo y María Mercedes Herrera. Bogotá, 19 de enero de 2011 .

Conversación entre Gustavo Sorzano y María Mercedes Herrera, Ubaque, 9 de julio de 2011 .

Conversación entre Orlando Gómez Pico y María Mercedes Herrera. Bogotá, 22 de julio de 201 I.

Conversación entre Hernando González Arrázola y María Mercedes Herrera, Bogotá, 6 de septiembre de 2012.

\section{Documentos sonoros en Colección GUSTAVO SORZANO}

Documento sonoro I, Material for Momentum One, cinta magnetofónica, 1968, digitalizados en formato WMA, duración: 18:03.

Documento sonoro 4, Música = Sonido Organizado, primera parte, cinta magnetofónica, 1968, digitalizado en formato WMA, duración: 33:13.

Documento sonoro 5, Música = Sonido Organizado, segunda parte, cinta magnetofónica, 1968, digitalizado en formato WMA, duración: 28: 10.

\section{Fuentes secundarias}

BARRIOS, Álvaro. Orígenes del arte conceptual en Colombia (Bogotá: Alcaldía Mayor de Bogotá, D.C., 1999).

BEJARANO, Mauricio. "1965. Música electroacústica colombiana.2006”, en Gustavo Zalamea ed., Arte y localidad modelos para desarmar. (Bogotá: Universidad Nacional de Colombia, 2006), págs. 27-35.

CORTÉS, María Clara. "Acercamientos a la obra de Antonio Caro". Tesis Maestría en Historia y Teoría de la Arquitectura y el Arte (Bogotá, Universidad Nacional de Colombia, 200I).

DREZNER, Manuel. "Arte y cultura", El Espectador, 3 de febrero de 1969.

DREZNER, Manuel. "Preguntas y respuestas", El Espectador, I de septiembre de 1970.

HERRERA Buitrago, María Mercedes. "Arquitectura del Sonido: evento inaugural de Música Viva en Bogotá. Año 1969", Ensayos. Historia y teoría del arte, no. 22 (2012): 6-29. Bogotá, Universidad Nacional de Colombia.

HERRERA Buitrago, María Mercedes. "Gustavo Sorzano y el arte conceptual en Colombia: tres momentos vitales", Calle 14. Revista de investigación en el campo del arte 6, no. 8 (2012): | 44- |6I. Bogotá, Universidad Distrital Francisco José de Caldas. 
HERRERA Buitrago, María Mercedes. Emergencia del Arte Conceptual en Colombia (1968-1982) (Bogotá: Editorial Pontificia Universidad Javeriana, 20 I I).

HERRERA Buitrago, María Mercedes. Gustavo Sorzano: pionero del arte conceptual en Colombia, X Premio de Ensayo histórico, teórico o crítico sobre el campo del arte colombiano, (en proceso de publicación por IDARTES).

JARAMILLO, Carmen María. "Manifestaciones de la crisis del arte moderno en Colombia: 1968-1978". Tesis Maestría en Historia y Teoría de la Arquitectura y el Arte (Bogotá, Universidad Nacional de Colombia, 200 I).

M.D.T. "El arte y la cultura", El Espectador, I de septiembre de 1970.

MORGAN, Robert P. La música del siglo XX (Madrid: Ediciones Akal, S.A., 1994). 